Saudi Journal of Biomedical Research

Abbreviated Key Title: Saudi J Biomed Res ISSN 2518-3214 (Print) |ISSN 2518-3222 (Online)

\title{
Retrospective Study of Fine Needle Aspiration Cytology of Thyroid Lesions According to the Bethesda System for Reporting Thyroid Cytopathology in El-Beida City
}

\author{
Raba M abdalkarem ${ }^{1}$, Marfoua S Ali ${ }^{2 *}$, Asma AM Abdalraziq ${ }^{1}$ and Tarek R S Alag ${ }^{3}$ \\ ${ }^{1}$ Histopathology Department, Faculty of Medicine, Omar Al-Mukhtar University, El -Beida-Libya \\ ${ }^{2}$ Zoology Department, Faculty of Science, Omar Al-Mukhtar University, El -Beida-Libya \\ ${ }^{3}$ Communication Engineering, Higher Institute of Comprehensive Professions, El -Beida-Libya
}

DOI: $10.36348 /$ sjbr.2019.v04i11.003

| Received: 07.11.2019 | Accepted: 14.11.2019| Published: 20.11 .2019

*Corresponding author: Marfoua S Ali

Abstract

Fine needle aspiration cytology (FNAC) plays important role in diagnosis of thyroid lesions. However conventional reporting of cytology lack standardize format. The Bethesda System for Reporting Thyroid Cytopathology (TBSRTC) presented at Bethesda in 2007 to address this barrier and facilitate communication between cytopathology's and clinician. This study was designed to classify thyroid FNAC according to TBSRTC, calculate malignancy risk by analytical cross sectional study. All the FNAC of thyroid lesions came during August 2013 to December 2014 were classified in to six categories of TBSRTC. Distribution of cases in each category was calculated. Cytopathology examination carried out whenever tissue was available and malignancy risk calculated. A total number 115 patients was enrolled to this study, 96 $(83.48 \%)$ females and $19(16.52 \%)$ males. The patients' ages ranged from 17 years to 80 years. The highest prevalence was noted in age groups 41-50 years followed with age groups 31-40 years with for both genders. All FNAS results were classified in to six categories of TBSRTC. The highest prevalence was recorded with benign with $51.3 \%$, followed by A.U.S with $14.7 \%$ then U.N.S with $11.3 \%$. Use of TBSRTC for thyroid FNAC reporting helps to highlight increased malignancy risk associated with different classification and malignant categories related to cytology of thyroid lesions.

Keywords: Bethesda system, cytology, malignancy risk, thyroid.

Copyright @ 2019: This is an open-access article distributed under the terms of the Creative Commons Attribution license which permits unrestricted use, distribution, and reproduction in any medium for non-commercial use (NonCommercial, or CC-BY-NC) provided the original author and source are credited.

\section{INTRODUCTION}

Thyroid enlargement has high prevalence rate reaching up to $4-7 \%$ of general population [1]. Majority of thyroid swellings are non-neoplastic and do not always require surgical intervention. Less than $5 \%$ of thyroid nodules are malignant [1]. Thyroid surgeries can be associated with lifelong thyroid hormone dependence and hypoparathyroidism in addition to the immediate operative risks involved [2]. If an accurate preoperative diagnosis can be made, unnecessary surgery can be avoided in benign conditions [2]. The initial preoperative screening procedures include ultrasonography, fine needle aspiration cytology (FNAC) and radio nucleotide scan. Among these, the FNAC is considered the most accurate diagnostic modality [3]. The Bethesda system of thyroid cytologyreporting makes the reports clinically relevant and helps the clinicians to take appropriate therapeutic interventions [4]. FNAC is a well-established outpatient procedure used in primary diagnosis of thyroid swellings and assumed dominant role in the management mainly to rule out need of surgery [5, 6]. It has gained acceptance in countries like the UK and USA since 1970s [7]. Currently it is practised worldwide and is the investigation of choice in thyroid, breast, and lymph node swellings. The technique has been shown to be simple, safe and cost-effective [8, 9]. However, the success of FNAC is contingent upon several important contributing influences including aspirator experience, skilful interpretation and rational analysis $[10,11]$. Malignancy in dissected thyroid is now above $50 \%$ of cases compare to $14 \%$ before wide spread use of FNAC [12,13]. The Bethesda system for reporting thyroid cytopathology (TBSRTC) was established to resolve this problem. Upon TBSRTC categories, there are six diagnostic categories of lesions: non-diagnostic/unsatisfactory (ND/UNS); benign; atypical follicular lesion of undetermined significance; follicular lesion/suspicious for follicular neoplasm (FN/SFN); suspicious for malignancy (SM); and malignant [14] (Table 1). These six diagnostic categories of the Bethesda system have individual 
implied risks of malignancy that influence management paradigms [14]. This retrospective study was aimed to analysis results from FNAC of thyroid lesions according to the TBSRTC categories in El-Beida City, Libya.

Table-1: The Bethesda System for Reporting Thyroid Cytopathology. Diagnostic category risk of malignancy (\%) and usual management [14]

\begin{tabular}{|c|c|c|}
\hline Diagnostic Category & TBSRTC category Description Comments & Risk of malignancy (\%) \\
\hline $\begin{array}{l}\text { 1.Unsatisfactory or } \\
\text { Non-diagnostic } \\
\text { (U.N.S) }\end{array}$ & $\begin{array}{l}\text { Not contain at least six well preserved and well stained follicular } \\
\text { groups each having at least ten cells. Thick abundant colloid as in } \\
\text { colloid nodule not required presence of minimum cells for } \\
\text { satisfactory aspiration. Thyroid cyst containing only histiocytes } \\
\text { are unsatisfactory. }\end{array}$ & 1. 0.1 to 0.4 \\
\hline 2.Benign & $\begin{array}{l}\text { Benign Cytomorphological features related to } \\
\text { colloid/adenomatoid goiter, thyroiditis and thyrotoxicosis. Benign } \\
\text { findings as reactive changes, radiation changes, cyst lining cells } \\
\text { and amyloid can be mentioned as descriptive diagnosis. }\end{array}$ & to 3 \\
\hline $\begin{array}{l}\text { 3.Atypia of } \\
\text { Undetermined } \\
\text { Significance (A.U.S) }\end{array}$ & atypical follicular lesion of undetermined significance & $\sim 5$ to 15 \\
\hline $\begin{array}{l}\text { 4.Follicular } \\
\text { Neoplasm or } \\
\text { Suspicious (F.N) }\end{array}$ & $\begin{array}{l}\text { Cytomorphological features of moderate to high cellularity, scant } \\
\text { or absent colloid, redominant microfollicular or trabecular } \\
\text { configuration of follicular cells in repetitive pattern. } \\
\text { Cytomorphological features of Hurthle cell neoplasm included in } \\
\text { this category }\end{array}$ & 15 o 30 \\
\hline $\begin{array}{l}\text { 5.Suspicious for } \\
\text { Malignancy (S.M) }\end{array}$ & $\begin{array}{l}\text { Cytolomorphological features suggestive of, but not definitive of, } \\
\text { papillary carcinoma, medullary carcinoma or lymphoma. Only } 1 \\
\text { or } 2 \text { changes for papillary carcinoma present focally or sparse } \\
\text { cellularity make it difficult to diagnose papillary carcinoma with } \\
\text { confidence. }\end{array}$ & $60 \quad$ o 75 \\
\hline 6. Malignant & $\begin{array}{l}\text { Papillary carcinoma, Medullary carcinoma, Lymphoma. Category } \\
\text { Number of cytology cases Percentages of cytology cases }\end{array}$ & 97 to 99 \\
\hline
\end{tabular}

\section{MATERIALS AND METHODS}

All the cases referred in our cytology laboratory for thyroid FNAC from August 2013 to December 2014 were included in this study. Aspirations were carried out by the cyto-pathologist and stained with Hematoxylene and Eosin after aspiration from 22 and 24 Gauge needle having $2.5 \mathrm{~cm}$ length and $10 \mathrm{cc}$ syringe without applying malignancy risks for nondiagnostic and benign category were zero as no cases were reported as malignant by cytology examination. Data gathered were compared with TBSRTC categories and risk for malignancy was calculated.

\section{RESULTS}

During the period of study from August 2013 to December 2014, total of 115 FNAC of thyroid were carried out in our cytology department. A total number 115 patients was enrolled to this study, 96 (83.48\%) females and $19(16.52 \%)$ males. The female: male incidence ratio was 5:1. The patients' ages ranged from 17 years to 80 years. The mean age for all the patients at diagnosis was $40.6 \pm 11.8$ years. Upon age groups, (as each group consist of 10 years intervals), highest prevalence was noted in age groups 41-50 years followed with age groups 31-40 years with for both genders. Lowest prevalence was observed in young and old patients (Table 2). All FNAC results were classified in to six categories of TBSRTC. Table: 2 show number of cases in each category. Out of 115 cases of thyroid cytology. Table 3 was shown percentage distribution of cases according to TBSRTC categories, which include unsatisfactory or non-diagnostic (U.N.S), benign, atypia of undetermined significance (A.U.S), follicular neoplasm or suspicious (F.N) (Figure 1 A and B), suspicious for malignancy (S.M) and malignant (Figure $1 \mathrm{C}$ and D). The highest prevalence was recorded with benign with $51.3 \%$, followed by A.U.S with $14.7 \%$ then U.N.S with $11.3 \%$. Table 4 was shown correlation between age groups and number of cases upon results from FANC according to TBSRTC categories for each gender separately. Most benign and A.U.S cases was recorded with female at age group (20-50). Malignant diagnosis was found at age group (20-49) and (40-60 in female and male respectively. 
Table-2: Age distribution for 115 patients, number with percentage for each gender separately

\begin{tabular}{|c|c|c|}
\hline Age (Years) & Male. N (\%) & Female. $\mathbf{N}(\%)$ \\
\hline 15- 20 & $1(5.3)$ & $4(4.2)$ \\
\hline 21- 30 & $2(10.5)$ & $18(18.8)$ \\
\hline 31- 40 & $5(26.3)$ & $29(30.2)$ \\
\hline 41- 50 & $9(47.4)$ & $32(33.3)$ \\
\hline $\mathbf{5 1 - ~ 6 0}$ & $2(10.5)$ & $7(7.3)$ \\
\hline 61- 70 & 0 & $3(3.1)$ \\
\hline $\mathbf{7 1 - 8 0}$ & 0 & $3(3.1)$ \\
\hline Total & 19 & 96 \\
\hline
\end{tabular}

Table-3: Distribution of FANC results among 115 patients according to TBSRTC categories.

\begin{tabular}{|l|c|}
\hline \multicolumn{1}{|c|}{ Diagnosis } & No of patients (\%) \\
\hline Unsatisfactory or Non-diagnostic (U.N.S) & $13(11.3)$ \\
\hline Benign & $59(51.3)$ \\
\hline Atypia of Undetermined Significance (A.U.S) & $17(14.8)$ \\
\hline Follicular Neoplasm or Suspicious (F.N) & $11(9.6)$ \\
\hline Suspicious for Malignancy (S.M) & $9(7.8)$ \\
\hline Malignant & $6(5.2)$ \\
\hline
\end{tabular}

Table-4: Relation between age groups for each gender separately and results of FANC according to TBSRTC

\begin{tabular}{|c|c|c|c|c|c|c|c|c|c|c|c|c|}
\hline \multirow{3}{*}{$\begin{array}{l}\text { Age } \\
\text { (Years) }\end{array}$} & \multirow{2}{*}{\multicolumn{2}{|c|}{ U.N.S }} & \multirow{2}{*}{\multicolumn{2}{|c|}{ Benign }} & & ategorie & & & & & & \\
\hline & & & & & \multicolumn{2}{|c|}{ A.U.S } & \multicolumn{2}{|l|}{ F.N } & \multicolumn{2}{|l|}{ S.M } & \multicolumn{2}{|c|}{ Malignant } \\
\hline & Male & Female & Male & Female & Male & Female & Male & Female & Male & Female & Male & Female \\
\hline $15-20$ & 0 & 0 & 0 & 4 & 0 & 0 & 0 & 0 & 0 & 0 & 0 & 0 \\
\hline 21-30 & 0 & 1 & 1 & 10 & 1 & 3 & 2 & 1 & 0 & 1 & 0 & 2 \\
\hline $31-40$ & 0 & 6 & 2 & 11 & 1 & 6 & 1 & 2 & 0 & 3 & 0 & 1 \\
\hline 41-50 & 1 & 4 & 5 & 17 & 0 & 6 & 0 & 4 & 1 & 1 & 1 & 0 \\
\hline $51-60$ & 0 & 0 & 1 & 6 & 1 & 0 & 0 & 0 & 0 & 0 & 1 & 1 \\
\hline 61-70 & 0 & 1 & 0 & 0 & 0 & 0 & 0 & 0 & 0 & 2 & 0 & 0 \\
\hline $71-80$ & 0 & 0 & 0 & 0 & 0 & 1 & 0 & 1 & 0 & 1 & 0 & 0 \\
\hline Total & 1 & 12 & 9 & 48 & 3 & 16 & 3 & 8 & 1 & 8 & 2 & 4 \\
\hline
\end{tabular}

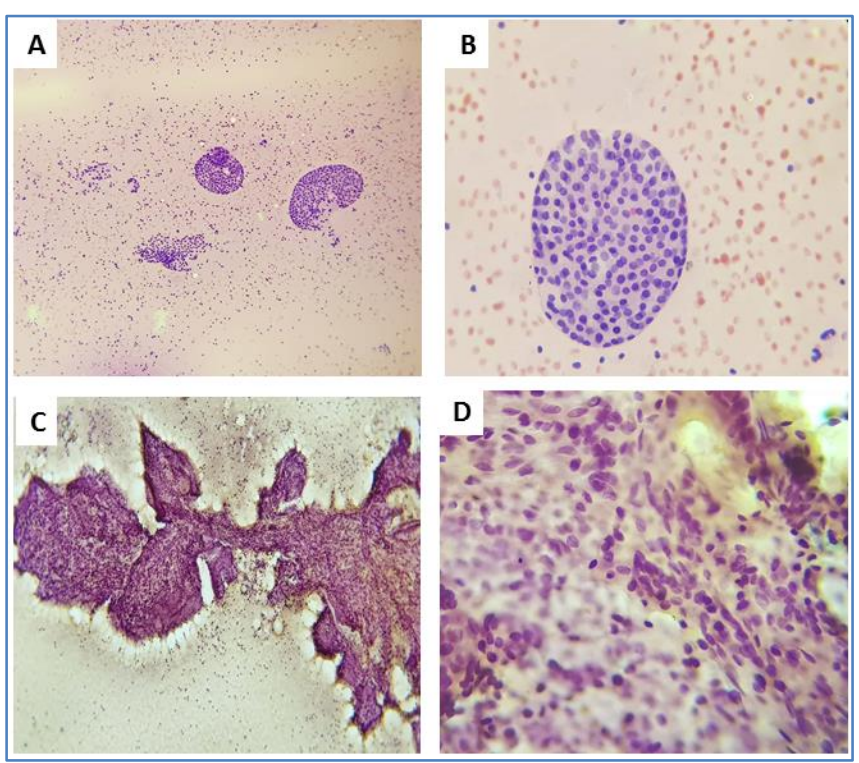

Fig-1: Fine needle aspiration cytology of follicular neoplasm or suspicious, follicular cells arranged in a flat sheet (H\&E stain on thin prep slide X 40 (A) and X 200 (B)). Fine needle aspiration cytology of papillary thyroid carcinoma showing cells with nuclear features of thyroid papillary carcinoma (nuclear groove pattern) (H\&E stain on thin prep slide X200 (C) and X 400 (D))

\section{DISCUSSION}

Thyroid diseases are, arguably, among the commonest endocrine disorders worldwide second only to diabetes [15]. In current study, the age of the participants ranges from 15-80 years, with median of 40 years, female subjects were also commonly affected and male to female ratio was 1:5 in our study. These observations were agreed to recent study at same City 
$[16,17]$. The FNAC biopsy is the most reliable, safe, and cost-effective diagnostic tool used in the definitive evaluation of thyroid nodules, especially when done under BSRTC-guidance. FANC also has a 95-97\% accuracy rate [15-17]. It also use highly sensitive imaging modalities allowing for identification of smaller lesions as well as improved awareness of the utility of FNAC in the evaluation of thyroid nodules. The main information one wants from FNAC is to distinguish a malignant lesion from a benign one. This distinction has dramatically reduced the surgery rates in thyroid pathologies [18]. Cytological diagnosis of thyroid lesions at this study is influenced by the BSRTC- guideline which has six categories. The current study was undertaken to evaluate the correlation between cytology and age and gender. It is of utmost importance because the treatment is greatly influenced by the FNAC report. The surgical for benign nodules is very common because most of the patients are referred to the hospital for surgical intervention. In current study, the highest prevalence was recorded with benign with $51.3 \%$, followed by A.U.S with $14.7 \%$ then U.N.S with $11.3 \%$. As FNAC is mainly aimed to rule out malignancy it should have a low false-negative rate, acceptable sensitivity and specificity for detection of malignancy and high negative predictive value. The reported sensitivity of thyroid FNAC ranges from $65 \%$ to $99 \%$ and its specificity from $72 \%$ to $100 \%$ [18-20]. This indicated that ability of FNAC to detect malignancy. This study included 115 patients with the diagnosis S.M and malignancy were found 7.8 and 5.2 $\%$ respectively. This is in agreement with the recommended rate of 5-15\% described in BSRTC [21]. In conclusion, use of TBSRTC for thyroid cytopathology reporting helps to improve communication between cytopathologist and clinicians along with inter-laboratory agreement for results lead to most effective management [22]. Categories like F.N, S.M and malignancy are associated with high malignancy risk and emphasis importance of TBSRTC.

\section{REFERENCES}

1. Brander, A., Viikinkoski, P., Nickels, J., \& Kivisaari, L. (1991). Thyroid gland: US screening in a random adult population. Radiology, 181(3), 683-687.

2. Ku, C. F., Lo, C. Y., Chan, W. F., Kung, A. W., \& Lam, K. S. (2005). Total thyroidectomy replaces subtotal thyroidectomy as the preferred surgical treatment for Graves' disease. ANZ journal of surgery, 75(7), 528-531.

3. Kant, U., Pratap, V., \& Kamal, A. K. Comparative Study of Preoperative Fine Needle Aspiration Cytology And Ultrasonography with Postoperative Histopathology of Thyroid Nodule.

4. Sukumaran, R., Kattoor, J., Pillai, K. R., Ramadas, P. T., Nayak, N., Somanathan, T., ... \& Sebastian, P. (2014). Fine needle aspiration cytology of thyroid lesions and its correlation with histopathology in a series of 248 patients. Indian journal of surgical oncology, 5(3), 237-241.

5. Nggada, H. A., \& Khalil, M. I. A. (2003). Fine needle aspiration cytology [FNAC] technique as a diagnostic tool of tumours in the University of Maiduguri Teaching Hospital, Nigeria. Highland Medical Research Journal, 1(3), 28-30.

6. Tabaqchali, M. A., Hanson, J. M., Johnson, S. J., Wadehra, V., Lennard, T. W., \& Proud, G. (2000). Thyroid aspiration cytology in Newcastle: a six year cytology/histology correlation study. Annals of the Royal College of Surgeons of England, 82(3), 149.

7. Nasuti, J. F., Gupta, P. K., \& Baloch, Z. W. (2002). Diagnostic value and cost-effectiveness of on-site evaluation of fine-needle aspiration specimens: review of $\quad 5,688 \quad$ cases. Diagnostic cytopathology, 27(1), 1-4.

8. Kini, U., Buch, A., \& Bantwal, G. (2006). Role of FNA in the medical management of minimally enlarged thyroid. Diagnostic cytopathology, 34(3), 196-200.

9. Saddique, M., Umair-Ul-Islam, P. I., \& Baloch, Q. (2008). FNAC: A reliable diagnostic tool in solitary thyroid nodule and multinodular goiter. Age, 24(3), 20.

10. Cibas, E. S. (2010). Fine-needle aspiration in the work-up of thyroid nodules. Otolaryngologic Clinics of North America, 43(2), 257-271.

11. Patel, M. M., Patel, K., Kaptan, K. R., Italiya, S. L., \& Saini, G. (2013). Fine needle aspiration cytology as a first line investigation in thyroid lesions. Natl J Med Res, 3(2), 106-10.

12. Nakrangsee, S. (2018). Cytopathology Reporting using the New Bethesda System of Thyroid FNAC and Correlation with Histopathological Follow-up: A Three-Year Study of Routine Service at Rajavithi Hospital. JOURNAL OF THE MEDICAL ASSOCIATION OF THAILAND, 101(2), 122.

13. Son, Y. I., Jeong, H. S., Baek, C. H., Chung, M. K., Ryu, J., Chung, J. H., ... \& Choi, J. (2008). Extent of prophylactic lymph node dissection in the central neck area of the patients with papillary thyroid carcinoma: comparison of limited versus comprehensive lymph node dissection in a 2-year safety study. Annals of Surgical Oncology, 15(7), 2020.

14. Cibas, E. S., \& Ali, S. Z. (2009). The Bethesda system for reporting thyroid cytopathology. Thyroid, 19(11), 1159-1165.

15. Mohanty, S., Amruthlal, W., Reddy, G. C., Kusumanjali, G., Kanagasabapathy, A. S., \& Rao, P. (2008). Diagnostic strategies for subclinical hypothyroidism. Indian journal of clinical biochemistry, 23(3), 279.

16. Abdalla, A. M., Alhdad, Z. A. S., Ali, M. S. (2019). Study about Sonographic Features of Thyroid Nodules to Differentiation between Benign and Malignant Among Patients from El- 
Beida City. Saudi Journal of Biomedical Research (SJBR), 4, 285.

17. Ali, M., Khaled, F., Moftah, S., Ibrahim, M.(2017). Prevalence of Thyroid Functions \& associated with sex and age in Northeast of Libya Global Scientific Journal of Biology, 1, 1.

18. Sidawy, M. K., Vecchio, D. M. D., \& Knoll, S. M. (1997). Fine-needle aspiration of thyroid nodules: correlation between cytology and histology and evaluation of discrepant cases. Cancer Cytopathology: Interdisciplinary International Journal of the American Cancer Society, 81(4), 253-259.

19. Caraway, N. P., Sneige, N., \& Samaan, N. A. (1993). Diagnostic pitfalls in thyroid fine-needle aspiration: a review of 394 cases. Diagnostic cytopathology, 9(3), 345-350.
20. Sharma, C. (2015). Diagnostic accuracy of fine needle aspiration cytology of thyroid and evaluation of discordant cases. Journal of the Egyptian National Cancer Institute, 27(3), 147153.

21. Thakkar, B., Patel, P. J., Mangar, U., Shiladariya, P., Suthar, N. B., \& Patel, P. (2015). Retrospective study of fine needle aspiration cytology of thyroid lesions according to the Bethesda System for Reporting Thyroid Cytopathology (TBSRTC). Int J Res Med, 4(4), 132-136.

22. Ozluk, Y., Pehlivan, E., Gulluoglu, M. G., Poyanli, A., Salmaslioglu, A., Colak, N., \& Yilmazbayhan, D. (2011). The use of the Bethesda terminology in thyroid fine-needle aspiration results in a lower rate of surgery for nonmalignant nodules: a report from a reference center in Turkey. International journal of surgical pathology, 19(6), 761-771. 